\title{
Synthesis of magnetic hollow carbon nanospheres with superior microporosity for efficient adsorption of hexavalent chromium ions
}

\author{
Lu-Hua Zhang, Qiang Sun, Chao Yang and An-Hui Lu*
}

\begin{abstract}
Microporous hollow carbon nanospheres were prepared through the polymerization of 2,4-dihydroxybenzoic acid and formaldehyde in the presence of ammonia and tactfully using chelating zinc species as dynamic porogens during the carbonization step to create extra micropores. $\mathrm{The} \mathrm{Cr}(\mathrm{VI})$ maximum adsorption capacity of microporous hollow carbon spheres consequently increase from $139.8 \mathrm{mg} \mathrm{g}^{-1}$ of pristine hollow carbon spheres to $199.2 \mathrm{mg} \mathrm{g}^{-1}$. Owing to the presence of the carboxyl groups in the polymer matrix, $\mathrm{Zn}^{2+}$ ions can be easily introduced into the hollow polymer spheres through complexation process. During carbonization, high temperature treatment results in the reduction of $\mathrm{Zn}^{2+}$ to metallic $\mathrm{Zn}$ and subsequent evaporation of $\mathrm{Zn}$, consequently forming nanospaces and nanopaths in the carbon shell. As little as $8.6 \mathrm{wt} . \% \mathrm{Zn}^{2+}$ in the polymer matrix can increase the micropore volume by $133 \%$ and the specific surface area by $86 \%$. The microporous hollow carbon spheres can be made magnetic by anchoring them to $14.0 \mathrm{wt} . \% \gamma-\mathrm{Fe}_{2} \mathrm{O}_{3}$ nanoparticles, thus producing a highly efficient $\mathrm{Cr}(\mathrm{VI})$ adsorbent. The maximum adsorption capacity measured was 233.1 $\mathrm{mg} \mathrm{g}^{-1}$, which is significantly higher than other reported carbon-based adsorbents. After adsorption, the magnetic microporous hollow carbon spheres can be flexibly separated using an external magnet.
\end{abstract}

\section{INTRODUTION}

Hexavalent chromium is of high global environmental concern due to its high solubility in water, toxicity, non-biodegradation and its tendency to accumulate in living organisms. Various approaches have been developed for the removal of $\mathrm{Cr}(\mathrm{VI})$, including ion exchange, chemical precipitation, solvent extraction, membrane filtration, electrochemical treatment and adsorption. Among the various removal processes, fundamental studies have shown that adsorption is the most promising method for industrial applications due to its easy and safe mode of operation, low cost and wide availability of adsorptive materials [1]. A variety of materials including raw and modified ligno- cellulosic materials [2-4], $\mathrm{TiO}_{2}$ microspheres [5], iron oxide [6-8], $\mathrm{Fe} @ \mathrm{Fe}_{2} \mathrm{O}_{3}$ [9], $\gamma$ - $\mathrm{Fe}_{2} \mathrm{O}_{3}$ [10-12], $\mathrm{Fe}_{3} \mathrm{O}_{4}$ [13-17], mixed maghemite-magnetite nanoparticles [18], $\mathrm{Al}_{2} \mathrm{O}_{3}$ [19], polymer-based composites [20-23], a graphene oxide (GO)-based composite adsorbent [24], and activated carbon [25-28] have been explored and used in the removal of $\mathrm{Cr}(\mathrm{VI})$. Among these adsorbents, carbonaceous porous materials have been successfully used in the removal of $\mathrm{Cr}$ (VI) because of their acid and alkali corrosion resistance, excellent thermal and chemical stability and high adsorption capacity for heavy metals [29].

In contrast to bulk materials, the high specific surface area of nanoscale materials provides more surface active sites, and good dispersability in solution to help facilitate mass transfer [1,30]. In addition, micropores inherently possess a strong adsorption potential, and can strongly trap and adsorb guest species from the external environment [31]. One can thus envisage that nanosized carbon materials with abundant micropores directly open to the environment could provide fast kinetics and a high adsorption capacity. Furthermore, to easily retrieve these nanosized adsorbents from solution, a functionalized nanocarbon with a magnetic response would be ideal. Although several magnetic carbon adsorbents [12,31-36] have been reported for the removal of chromium, there is still a need to improve such adsorbents to have a high adsorption capacity.

It is worth mentioning that recent studies have shown that zinc species is good dynamic molecular porogens to create extra micropores [37-39]. These results show that $\mathrm{Zn}$ ions turn into $\mathrm{ZnO}$ during pyrolysis process. Further temperature increase can lead to the reduction of $\mathrm{ZnO}$ nanoparticles in the presence of carbon materials (carbothermal reduction), accompanied by the evaporation of $\mathrm{Zn}, \mathrm{CO}_{2}$, and $\mathrm{CO}$. The evaporation of the $\mathrm{Zn}$ species would create additional nanochannels that contribute to the ad-

State Key Laboratory of Fine Chemicals, School of Chemical Engineering, Dalian University of Technology, Dalian 116024, China

*Corresponding author (email: anhuilu@dlut.edu.cn) 
ditional micropore. Those methods not only removes zinc species without the necessity of acid washing but also results in accessible nanoscale porosity. Compared to conventional chemical activation, the method mentioned above can significantly reduce the dosage of zinc salt.

Under these considerations, we report a simple and efficient strategy for the synthesis of magnetic hollow carbon spheres with superior microporosity by using zinc species as dynamic molecular porogens, which show a superior maximum adsorption capacity of $233.1 \mathrm{mg} \mathrm{g}^{-1}$ for $\mathrm{Cr}(\mathrm{VI})$ from water and fast kinetics compared to other previously reported carbon-based adsorbents.

\section{EXPERIMENTAL SECTION}

\section{Materials}

2,4-Dihydroxybenzoic acid (DA) was obtained from Aldrich. Oleic acid, formaldehyde, ammonia solution (25\%), zinc chloride, $\mathrm{Fe}\left(\mathrm{NO}_{3}\right)_{3} \cdot 9 \mathrm{H}_{2} \mathrm{O}$, 1,5-diphenylcarbazide, phosphoric acid (85\%) and potassium dichromate were obtained from the Sinopharm Chemical Reagent Co. All chemicals were used as received without any further purification.

\section{Synthesis of hollow polymer and carbon nanospheres}

Hollow polymer nanospheres (HPSs) were synthesized following the previously reported method [38]. An emulsion solution was prepared by mixing oleic acid/ammonia (forming ammonium oleate) and DA/formaldehyde solution, and then transferred into an autoclave and hydrothermally aged for $4 \mathrm{~h}$ at $120^{\circ} \mathrm{C}$. Hollow carbon nanospheres (HCSs) were obtained by heating the HPSs to $910^{\circ} \mathrm{C}$ with a heating rate of $5^{\circ} \mathrm{C} \mathrm{min}^{-1}$ and holding them at that temperature for $3 \mathrm{~h}$ under an argon atmosphere.

\section{Synthesis of microporous hollow carbon nanospheres} HPSs were impregnated in aqueous $\mathrm{ZnCl}_{2}$ for $12 \mathrm{~h}$ to load the $\mathrm{Zn}^{2+}$ to obtain HPSs-Zn. The resultant HPSs-Zn were retrieved by centrifugation, washed with deionized water and ethanol to remove the $\mathrm{ZnCl}_{2}$ located outside the spheres, with final drying at $50^{\circ} \mathrm{C}$ for $12 \mathrm{~h}$. The obtained polymeric spheres HPSs- $\mathrm{Zn}$ were heated at $5^{\circ} \mathrm{C} \mathrm{min}^{-1}$ to $910^{\circ} \mathrm{C}$, where they were pyrolyzed for $3 \mathrm{~h}$ under an argon atmosphere. Finally, microporous hollow carbon nanospheres were synthesized, and these are called HCSsZn-910. For comparison, another sample, HCSs-Zn-750, was produced by pyrolysis at $750^{\circ} \mathrm{C}$, also for $3 \mathrm{~h}$.

\section{Synthesis of magnetic microporous hollow carbon spheres}

The microporous hollow carbon spheres (HCSs-Zn-910) were immersed in aqueous $\mathrm{Fe}\left(\mathrm{NO}_{3}\right)_{3} \cdot 9 \mathrm{H}_{2} \mathrm{O}(0.24 \mathrm{M})$ for 4 $\mathrm{h}$ at $30^{\circ} \mathrm{C}$ under vacuum. After centrifugation and washing with deionized water to remove $\mathrm{Fe}\left(\mathrm{NO}_{3}\right)_{3}$ on the external surfaces of the spheres, the product was dried at $50^{\circ} \mathrm{C}$ for $12 \mathrm{~h}$. The freshly dried product was then pyrolyzed at $400^{\circ} \mathrm{C}$ for $2 \mathrm{~h}$ under an argon flow to obtain the final product, denoted as Fe-HCSs-Zn-910.

\section{Characterization}

Thermogravimetric analysis was performed from room temperature to $700^{\circ} \mathrm{C}$ in air with a heating rate of $10^{\circ} \mathrm{C}$ $\mathrm{min}^{-1}$ using a thermogravimetric analyzer, STA449 F3 Jupiter (NETZSCH). X-ray diffraction (XRD) measurements were recorded with a Rigaku D/Max 2400 diffractometer using $\mathrm{Cu}$-Ka radiation $(\lambda=0.15406 \mathrm{~nm})$. Nitrogen adsorption isotherms were measured with a Micromeritics ASAP 3000 adsorption analyzer at 77.4 K. Before the measurements, all the samples were degassed at $200^{\circ} \mathrm{C}$ for $4 \mathrm{~h}$. The total pore volume $\left(V_{\text {total }}\right)$ was estimated from the amount adsorbed at a relative pressure of 0.95 . Scanning electron microscopy (SEM) investigations were carried out with a Hitachi S-4800 instrument at $3 \mathrm{kV}$. Transmission electron microscopy (TEM) images were obtained with a FEI Tecnai $\mathrm{G}^{2} 20 \mathrm{~S}$-Twin instrument operating at $200 \mathrm{kV}$. The samples for TEM analysis were prepared by dipping carbon-coated copper grids into the ethanol solutions of the products and drying at room temperature. IR spectra were collected on a Nicolet 6700 FTIR spectrometer.

\section{Cr(VI) removal experiments}

HCSs, HCSs-Zn-910 and Fe-HCSs-Zn-910 were used to remove $\mathrm{Cr}(\mathrm{VI})$ from aqueous acid solutions according to the method reported by Baikousi et al. [12]. Typically, 20 $\mathrm{mg}$ of the sample was added to a $100 \mathrm{~mL}$ aqueous solution of $\mathrm{K}_{2} \mathrm{Cr}_{2} \mathrm{O}_{7}$ (different concentrations of $\mathrm{Cr}(\mathrm{VI})$ : $5,10,15$, $20 \mathrm{mg} \mathrm{L}^{-1}$ ) and stirred at room temperature for $24 \mathrm{~h}$ in a closed vessel. The $\mathrm{pH}$ of the suspensions was adjusted to 3 by adding a $\mathrm{HCl}$ solution $(0.1 \mathrm{M})$. During the adsorption process ca. $0.3 \mathrm{~mL}$ of the $\mathrm{Cr}(\mathrm{VI})$ solution was extracted with a needle tube equipped with a membrane filter after different times $(0,0.15,0.5,1,2,3,6,9,12$, and $24 \mathrm{~h})$, and then diluted for colorimetric measurements. The $\mathrm{Cr}$ (VI) concentrations in the obtained solutions were determined using the 1,5-diphenylcarbazide method [12].

\section{RESULTS AND DISCUSSION}

The formation process of microporous hollow carbon spheres and magnetic microporous hollow carbon spheres is illustrated in Scheme 1. HPSs were prepared using a weak acid-base interaction-induced assembly. The func- 


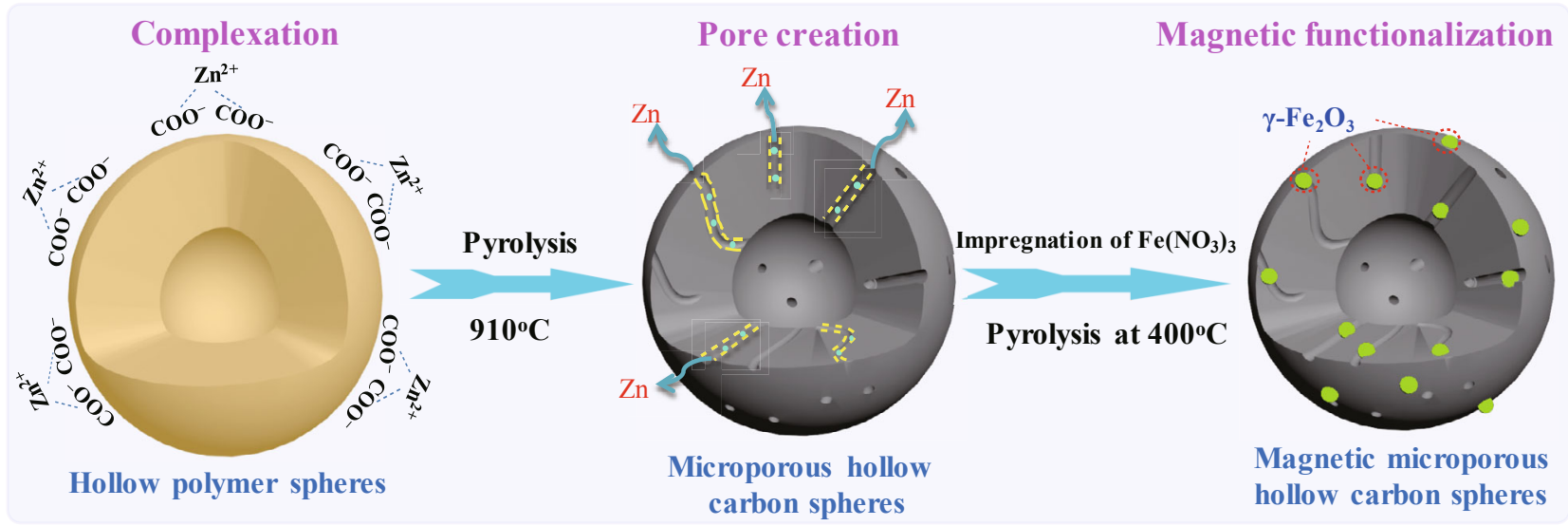

Scheme 1 Schematic illustration for the formation process of microporous hollow carbon spheres and magnetic microporous hollow carbon spheres.

tional shells were formed through the polymerization of 2,4-dihydroxybenzoic acid and formaldehyde in the presence of ammonia [40]. Due to the uniform distribution of abundant carboxyl groups in such a polymer, $\mathrm{Zn}^{2+}$ ions could be introduced into hollow polymer spheres through complexation process [40-43]. As the FTIR spectrum of HPSs-Zn in Fig. 1a shows, the new absorption at 1517 $\mathrm{cm}^{-1}$ is attributed to the antisymmetric stretching vibration of the carboxylate group $\left[v_{\mathrm{a}}(\mathrm{COO})\right]$, providing the complexation between the carboxyl groups in the polymer matrix and zinc ions [44]. During carbonization, $\mathrm{Zn}^{2+}$ was carbothermically reduced metallic $\mathrm{Zn}$ and a much higher temperature of $910^{\circ} \mathrm{C}$ (boiling point of $\mathrm{Zn}$ metal is $908^{\circ} \mathrm{C}$ ) results in the evaporation of $\mathrm{Zn}$. The escape trajectories of $\mathrm{Zn}$ consequently form the nanospaces and nanopaths in the carbon shell [37-39]. When the obtained microporous carbon spheres (HCSs-Zn-910) were immersed in aqueous iron nitrate under vacuum conditions, the aqueous iron nitrate entered the microporous carbon shell. The microporous hollow carbon spheres (Fe-HCSs-Zn-910) can be made magnetic by anchoring them to $14.0 \mathrm{wt} . \% \gamma-\mathrm{Fe}_{2} \mathrm{O}_{3}$ nanoparticles through further pyrolysis at $400^{\circ} \mathrm{C}$ under an argon flow. In order to corroborate the pore-creating function of metallic $\mathrm{Zn}$, two controlled samples were prepared. One (HCSs) is the direct pyrolysis product of hollow polymer nanospheres at $910^{\circ} \mathrm{C}$ and the other (HCSs-Zn-750) is the pyrolysis product of $\mathrm{Zn}^{2+}$-containing hollow polymer nanospheres at $750^{\circ} \mathrm{C}$ of below $\mathrm{Zn}$ evaporation temperature.

Structural properties of microporous hollow carbon spheres The porous structures of HCSs-Zn-910, HCSs-Zn-750 and HCSs were analyzed by nitrogen adsorption at $77.4 \mathrm{~K}$. Fig. $1 \mathrm{~b}$ shows that their nitrogen adsorption-desorption iso- therms are type-I in shape, indicating their microporous characteristics. The structural parameters are summarized in Table 1. Remarkably, sample HCSs-Zn-910 shows a high surface area of $1044 \mathrm{~m}^{2} \mathrm{~g}^{-1}$, approximately $86 \%$ and $50 \%$ higher than those of samples HCSs and HCSs-Zn-750, respectively. It should be noted that only $8.6 \mathrm{wt} \% \mathrm{Zn}^{2+}$ in a polymer matrix can significantly create $86 \%$ more specific surface area and $133 \%$ more micropore volume. The appreciable increases in specific surface area and micropore volume of HCSs-Zn-910 are attributed to the nanopaths by which the volatized $\mathrm{Zn}$ escaped. Specially, during carbonization, conventional micropores gradually emerged, and highly dispersed $\mathrm{Zn}^{2+}$ matrix embedded in the carbon matrix was reduced to $\mathrm{Zn}$. The vaporization of $\mathrm{Zn}$ subsequently led to the creation of nanopaths [37-39,45-47]. Meanwhile, the core-shell nanostructures of HCSs-Zn-910 are retained after pyrolysis at $910^{\circ} \mathrm{C}$, and the sphere sizes are ca. $200 \mathrm{~nm}$ (Figs $1 \mathrm{c}$ and d)

In order to detect changes in the $\mathrm{Zn}$ species at different stages of the carbonization process, HPSs, HPSs-Zn, the corresponding carbons HCSs, and HCSs-Zn-T (where T is the pyrolysis temperature), were all subjected to treatment in air at $700^{\circ} \mathrm{C}$ for $2 \mathrm{~h}$ and the final residues were then collected. As a result, white residues $(\mathrm{ZnO})$ were observed in samples HPSs-Zn and HCSs-Zn-750, of which the mass percentages of $\mathrm{ZnO}$ were respectively $10.7 \%$ and $17.1 \%$. No detectable residue was left after calcination of samples HPSs, HCSs and HCSs-Zn-910. The initial reactants are composed of $\mathrm{C}, \mathrm{H}, \mathrm{O}, \mathrm{N}$ and $\mathrm{Zn}$, and the boiling point of $\mathrm{ZnO}$ is $1800^{\circ} \mathrm{C}$, so it could be deduced that the solid residue of all samples after calcination at $700^{\circ} \mathrm{C}$ was $\mathrm{ZnO}$. This confirmed that $\mathrm{Zn}$ can escape from the carbon matrix during the high temperature $\left(910^{\circ} \mathrm{C}\right)$ pyrolysis process.

In contrast to conventional zinc chloride activation [48- 

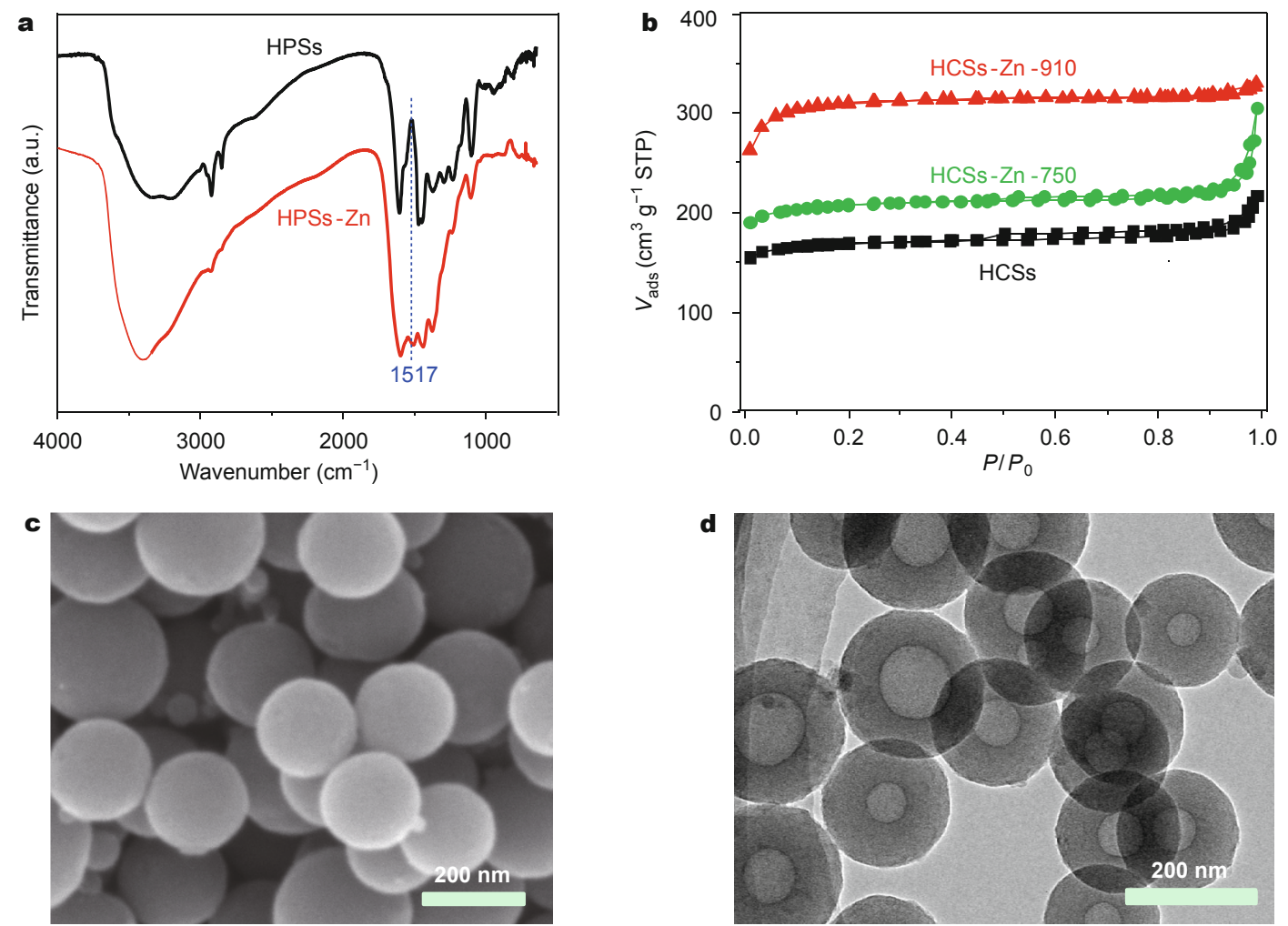

Figure 1 (a) FTIR spectra of HPS before and after complexation of zinc ions, (b) $\mathrm{N}_{2}$ sorption isotherms of HCSs, HCSs-Zn-750 and HCSs-Zn-910, (c) SEM image, and (d) TEM image of HCSs-Zn-910.

51], our method is more environmentally friendly due to the use of less zinc chloride and the omission of the hydrochloric acid washing step for the removal of the $\mathrm{ZnO}$ embedded in the carbon matrix. To prove this point, a series of comparative experiments were conducted. The zinc chloride activation process was performed using three different $\mathrm{ZnCl}_{2}$ to HPSs mass ratios of $0.18,0.74$ and 1 . To ensure complete mixing of $\mathrm{ZnCl}_{2}$ and HPSs, the HPSs were immersed in aqueous $\mathrm{ZnCl}_{2}$ for $0.5 \mathrm{~h}$ at $25^{\circ} \mathrm{C}$. After that, the samples were dried at $110^{\circ} \mathrm{C}$ for $24 \mathrm{~h}$, and then pyrolyzed at $910^{\circ} \mathrm{C}$ for $3 \mathrm{~h}$ under an argon flow to obtain the final $\mathrm{ZnCl}_{2} / \mathrm{HPSs}-n$ (where $n$ is the $\mathrm{ZnCl}_{2}$ to HPSs mass ratio). As shown in Table 1, when the $\mathrm{ZnCl}_{2}$ to HPSs mass ratio is 0.18 ( 8.6 wt. $\%$ of $\mathrm{Zn}^{2+}$ ), the $S_{\mathrm{BET}}$ of sample $\mathrm{ZnCl}_{2} / \mathrm{HPSs}-0.18$ is $701 \mathrm{~m}^{2} \mathrm{~g}^{-1}$ and $V_{\text {mic }}$ is $0.30 \mathrm{~cm}^{3} \mathrm{~g}^{-1}$, which are much lower than the corresponding values of HCSs-Zn-910. Even though the $\mathrm{ZnCl}_{2}$ to HPSs mass ratio is 0.74 , the specific surface area and pore volume of sample $\mathrm{ZnCl}_{2} / \mathrm{HPSs}-0.74$ are lower than those of HCSs-Zn-910. A literature survey shows that the mass ratio of $\mathrm{ZnCl}_{2}$ to raw material is generally in the range of $0.75 \sim 3$ in order to achieve a high specific surface area using conventional zinc chloride activation methods [48-50].

\section{Properties of the magnetic microporous hollow carbon spheres}

When HCSs-Zn-910 microporous spheres were immersed in aqueous $\mathrm{Fe}\left(\mathrm{NO}_{3}\right)_{3} \cdot 9 \mathrm{H}_{2} \mathrm{O}$ under vacuum conditions, the aqueous iron nitrate not only entered the microporous carbon shell, but also attached to the external surface. Iron nitrate on the external surfaces of the hollow carbon spheres was removed by subsequently washing with deionized water. Fe-based magnetic nanoparticles were formed through further pyrolysis of the above product at $400^{\circ} \mathrm{C}$ under an argon flow.

A TEM image of Fe-HCSs-Zn-910 (Fig. 2a) shows that a large number of iron oxide nanoparticles (dark spots) are randomly dispersed throughout the entire sample. Magnetic properties were studied using a vibrating sample magnetometer. Magnetization curves in Fig. $2 b$ indicate that Fe-HCSs-Zn-910 exhibits ferromagnetic behavior. The saturation magnetization is $4.58 \mathrm{emu} \mathrm{g}^{-1}$, indicating a magnetic separation capability [52]. Crystal phases of the iron oxide nanoparticles were characterized by XRD. As shown 
Table 1 Structural parameters of HCSs, HCSs-Zn-T, and $\mathrm{ZnCl}_{2} / \mathrm{HPSs}-n$

\begin{tabular}{|c|c|c|c|c|c|}
\hline Sample & $S_{\text {BET }}{ }^{\mathrm{a}}\left(\mathrm{m}^{2} \mathrm{~g}^{-1}\right)$ & $S_{\text {mic }}^{\mathrm{b}}\left(\mathrm{m}^{2} \mathrm{~g}^{-1}\right)$ & $V_{\text {total }}{ }^{\mathrm{c}}\left(\mathrm{cm}^{3} \mathrm{~g}^{-1}\right)$ & $V_{\text {mic }}{ }^{\mathrm{d}}\left(\mathrm{cm}^{3} \mathrm{~g}^{-1}\right)$ & Yield \\
\hline HCSs & 561 & 451 & 0.30 & 0.21 & $42.5 \%$ \\
\hline HCSs-Zn- $750^{\mathrm{e}}$ & 694 & 602 & 0.35 & 0.28 & $41.2 \%$ \\
\hline HCSs-Zn-910 & 1044 & 933 & 0.66 & 0.49 & $33.2 \%$ \\
\hline $\mathrm{ZnCl}_{2} /$ HPSs- 0.18 & 701 & 657 & 0.33 & 0.30 & $40.6 \%$ \\
\hline $\mathrm{ZnCl}_{2} / \mathrm{HPSs}-0.74$ & 978 & 892 & 0.53 & 0.43 & $29.1 \%$ \\
\hline $\mathrm{ZnCl}_{2} / \mathrm{HPSs}-1$ & 1202 & 1063 & 0.57 & 0.49 & $26.5 \%$ \\
\hline Fe-HCSs-Zn-910 & 910 & 885 & 0.44 & 0.40 & l \\
\hline
\end{tabular}

a) $S_{\mathrm{BET}}$ : specific surface area calculated by the BET method. b) $S_{\text {mic }}$ : micropore surface areacalculated by the t-plot method. c) $V_{\text {total: }}$ total pore volume at $P / P_{0}=0.95$. d) $V_{\text {mic }}$ : micropore volume calculated by the t-plot method. e) HCSs-Zn-750was washed with $3 \mathrm{M} \mathrm{HCl}$ solution byheating at around $90^{\circ} \mathrm{C}$ for $30 \mathrm{~min}$ to remove $\mathrm{ZnO}$.
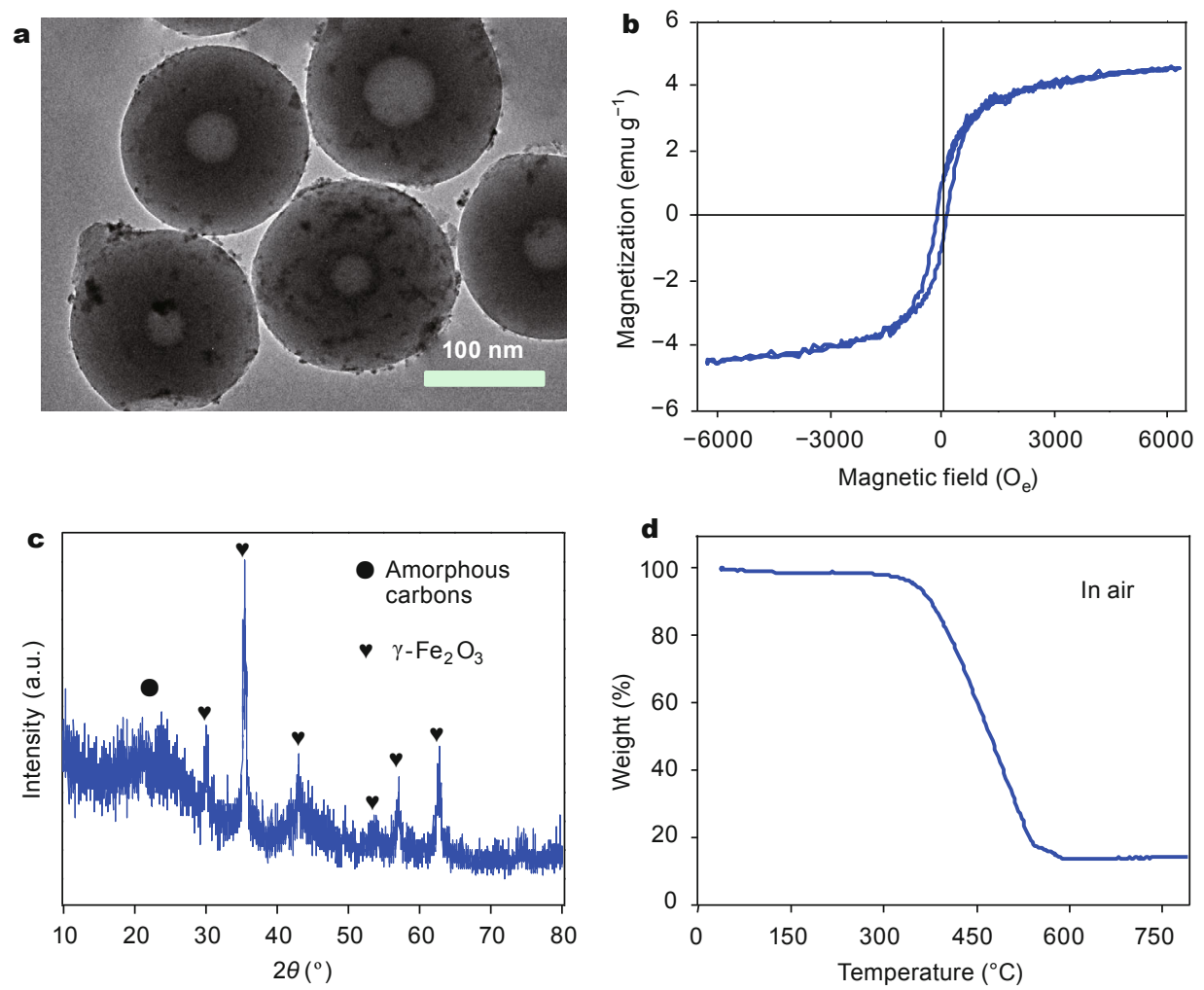

Figure 2 (a) TEM image, (b) room temperature magnetization curve, (c) XRD pattern, and (d) TG curve of Fe-HCSs-Zn-910.

in Fig. 2c, the XRD patterns of the Fe-HCSs-Zn-910 show a broad peak located at ca. $23.4^{\circ}(2 \theta)$, which is the characteristic peak of amorphous carbons. The other diffraction peaks are attributed to $\gamma-\mathrm{Fe}_{2} \mathrm{O}_{3}$. A literature survey showed that using porous carbon as the host and $\mathrm{Fe}\left(\mathrm{NO}_{3}\right)_{3} \cdot 9 \mathrm{H}_{2} \mathrm{O}$ as the iron oxide precursor, $\gamma-\mathrm{Fe}_{2} \mathrm{O}_{3}$ phase nanoparticles were usually obtained $[12,53,54]$. The magnetic $\gamma-\mathrm{Fe}_{2} \mathrm{O}_{3}$ nanoparticles not only provided a magnetic separation ability, but also an improved adsorption capacity (which will be discussed in detail later). TG results in Fig. $2 \mathrm{~d}$ show that the $\mathrm{Fe}_{2} \mathrm{O}_{3}$ content is 14.0 wt.\% for Fe-HCSs-Zn-910.

\section{Remediation experiments for $\mathrm{Cr}$ (VI) removal from aqueous solutions}

It is clear that at lower $\mathrm{pH}$ values $(\mathrm{pH} 1 \sim 4)$, the dominant species of hexavalent chromium is $\mathrm{HCrO}_{4}^{-}$, which gradually changes to $\mathrm{CrO}_{4}{ }^{2-}$ as the $\mathrm{pH}$ increases. Importantly, $\mathrm{HCrO}_{4}{ }^{-}$is more favorably adsorbed than $\mathrm{CrO}_{4}{ }^{2-}$ due 
to its lower adsorption free energy [12,55]. Thus, intense chromium adsorption occurred in the $\mathrm{pH}$ range where $\mathrm{HCrO}_{4}^{-}$species were dominant. Therefore, the $\mathrm{Cr}(\mathrm{VI})$ removal efficiency and kinetics for the HCSs, HCSs-Zn-910, and Fe-HCSs-Zn-910 from acid aqueous solutions $(\mathrm{pH}$ 3 ) were investigated by conducting a series of kinetic experiments. Fig. 3a shows the efficiency of $\mathrm{Cr}(\mathrm{VI})$ removal with an initial $\mathrm{Cr}(\mathrm{VI})$ concentration of $5 \mathrm{mg} \mathrm{L}^{-1}$, an adsorbent mass of $20 \mathrm{mg}$, a solution volume of $100 \mathrm{~mL}$, and an adsorption temperature of $25^{\circ} \mathrm{C}$. As the time progressed, the final removal efficiencies of all three samples reached $100 \%$. It was obvious that the performance of Fe-HCSsZn-910 and HCSs-Zn-910 was better than that of HCSs. Hence, the adsorption kinetics of all three samples were studied in detail. Based on the experimental values at the different initial concentrations listed in Table 2, it can be seen that the adsorption kinetics of samples fit perfectly to a pseudo-second-order model [56]. All the correlation coefficients $R^{2}$ are $>0.99$. The adsorption rate of Fe-HCSs$\mathrm{Zn}-910$ is $219.7 \times 10^{-3} \mathrm{~g} \mathrm{mg}^{-1} \mathrm{~min}^{-1}$ with an initial $\mathrm{Cr}(\mathrm{VI})$ concentration of $5 \mathrm{mg} \mathrm{L}^{-1}$.

The fast adsorption kinetics of Fe-HCSs-Zn-910 and HCSs-Zn-910 for Cr(VI) removal demonstrate that microporous carbon can effectively capture $\mathrm{Cr}(\mathrm{VI})$ from the external environment due to the strong adsorption potential of micropores. Meanwhile, the high specific surface area provides abundant active sites and can interact with Cr(VI). Fe-HCSs-Zn-910 also shows a higher adsorption rate than HCSs-Zn-910. This is possibly due to the fact that $\gamma$ - $\mathrm{Fe}_{2} \mathrm{O}_{3}$ nanoparticles increase electrostatic adsorption due to the formation of more $\mathrm{X}-\mathrm{OH}_{2}^{+}(\mathrm{X}=\mathrm{Fe}, \mathrm{C})$ groups. This effect is further translated into an increased capacity for the immobilization and reduction of $\mathrm{Cr}(\mathrm{VI})[13,14,18,57]$.

The adsorption isotherm experimental data obtained for all samples gave a good fit to the Langmuir model (Equations (1-2)) $\left(R^{2}>0.99\right)$, as shown in Figs $3 \mathrm{~b}$ and $\mathrm{c}$. This indicates monolayer adsorption with a high adsorption affinity and excellent saturation capacities. The values of the parameters from the Langmuir equation are summarized in Table 3. Clearly, the maximum adsorption capacity of Fe-HCSs-Zn-910 is $233.1 \mathrm{mg} \mathrm{g}^{-1}$, which is much larger than values reported for other carbon-based adsorbents $[12,31-36,58,59]$. The extraordinary adsorption capacity of Fe-HCSs-Zn-910 is attributed to the large specific surface area providing abundant surface active sites for the adsorption of $\mathrm{Cr}(\mathrm{VI})$ and the increased electrostatic adsorption of the $\gamma-\mathrm{Fe}_{2} \mathrm{O}_{3}$.

The Langmuir model:

$$
q_{\mathrm{e}}=\frac{b Q_{\mathrm{m}} C_{\mathrm{e}}}{1+b C_{\mathrm{e}}}
$$

Table 2 Kinetic constants for the adsorption of Cr(VI) on samples HCSs, HCSs-Zn-910, and Fe-HCSs-Zn-910

\begin{tabular}{|c|c|c|c|c|}
\hline Samples & {$[\mathrm{Cr}(\mathrm{VI})]_{0}\left(\mathrm{mg} \mathrm{L}^{-1}\right)$} & $k_{2} \times 10^{-3}\left(\mathrm{~g} \mathrm{mg}^{-1} \mathrm{~min}^{-1}\right)$ & $R^{2}$ & $\% \mathrm{E}(24 \mathrm{~h})$ \\
\hline \multirow{4}{*}{ Fe-HCSs-Zn-910 } & 5 & 219.7 & 0.999 & 100 \\
\hline & 10 & 16.2 & 0.998 & 100 \\
\hline & 15 & 4.3 & 0.998 & 100 \\
\hline & 20 & 1.1 & 0.997 & 100 \\
\hline \multirow{4}{*}{ HCSs-Zn-910 } & 5 & 149.8 & 0.997 & 100 \\
\hline & 10 & 13.3 & 0.996 & 100 \\
\hline & 15 & 2.4 & 0.999 & 100 \\
\hline & 20 & 0.6 & 0.998 & 100 \\
\hline \multirow{2}{*}{$\mathrm{HCSs}$} & 5 & 1.9 & 0.999 & 100 \\
\hline & 10 & 1.1 & 0.996 & 84.2 \\
\hline
\end{tabular}

Table 3 Langmuir isotherm parameters for the adsorption of $\mathrm{Cr}(\mathrm{VI})$ by all samples

\begin{tabular}{lccr}
\hline \multicolumn{1}{c}{ Sample } & $1 / Q_{\mathrm{m}}$ & $b$ & $\mathrm{Q}_{\mathrm{m}}\left(\mathrm{mg} \mathrm{g}^{-1}\right)$ \\
\hline Fe-HCSs-Zn-910 & 0.00429 & 3.06 & 233.1 \\
HCSs-Zn-910 & 0.00502 & 1.26 & 199.2 \\
HCSs & 0.00715 & 0.075 & 139.8 \\
\hline
\end{tabular}



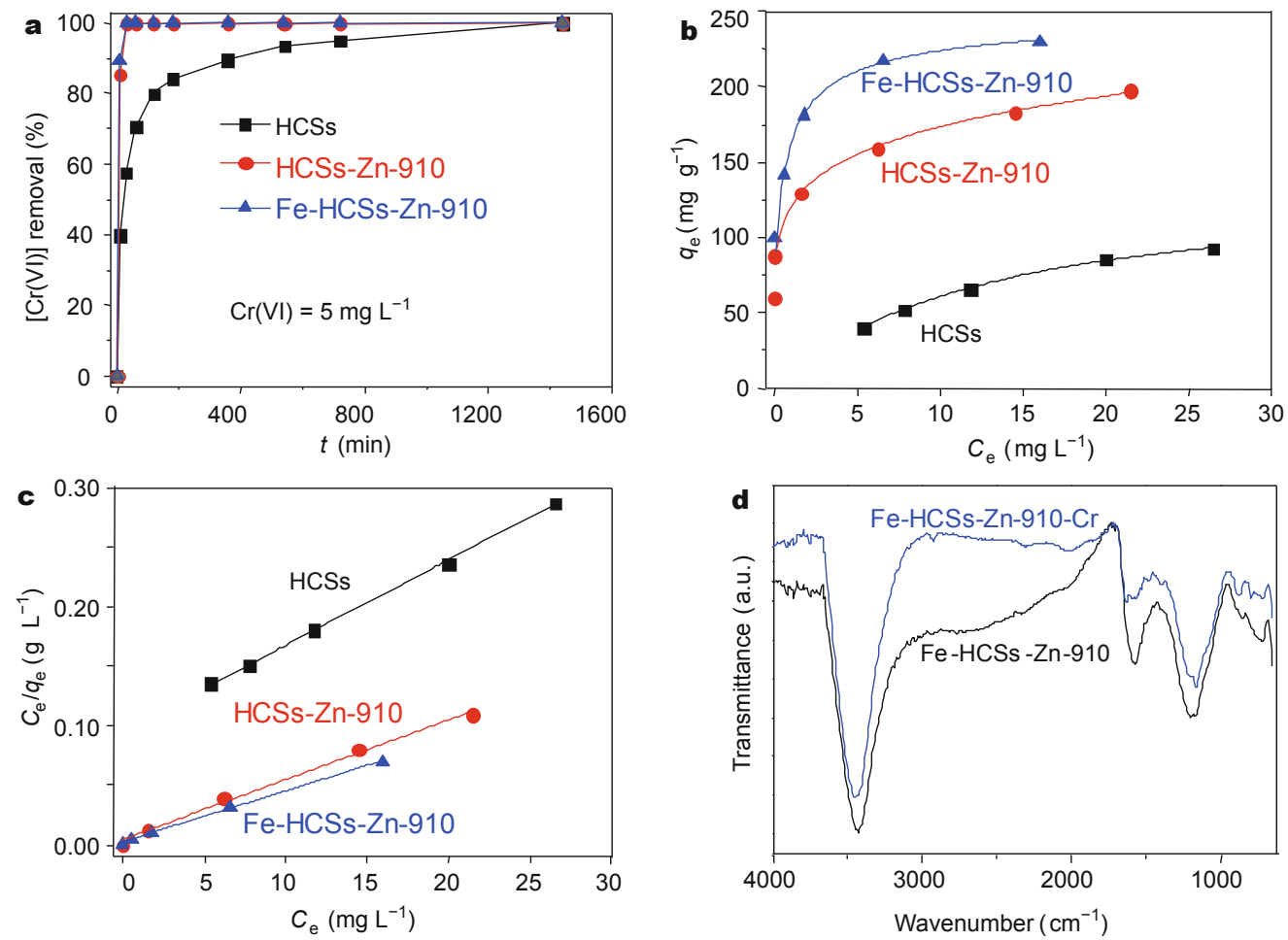

Figure 3 (a) Relationship between the $\mathrm{Cr}(\mathrm{VI})$ removal percentage and time at initial $\mathrm{Cr}(\mathrm{VI})$ concentration of $5 \mathrm{mg} \mathrm{L}^{-1}$, (b) adsorption isotherms at $25^{\circ} \mathrm{C}$, (c) $C_{\mathrm{e}} / q_{\mathrm{e}} v s . C_{\mathrm{e}}$ plot of sample HCSs, HCSs-Zn-910 and Fe-HCSs-Zn-910, and (d) FTIR spectra of Fe-HCSs-Zn-910 before and after adsorption of $\mathrm{Cr}(\mathrm{VI})$.

$$
\frac{C_{\mathrm{e}}}{q_{\mathrm{e}}}=\frac{1}{Q_{\mathrm{m}} b}+\frac{C_{\mathrm{e}}}{Q_{\mathrm{m}}}
$$

where $C_{\mathrm{e}}$ is the equilibrium concentration of $\mathrm{Cr}(\mathrm{VI})$ in the supernatant $\left(\mathrm{mg} \mathrm{L}^{-1}\right), q_{\mathrm{e}}$ is the amount of $\mathrm{Cr}(\mathrm{VI})$ adsorbed per mass of adsorbent $\left(\mathrm{mg} \mathrm{g}^{-1}\right)$ after adsorption equilibrium, $Q_{\mathrm{m}}$ refers to the maximum adsorption capacity corresponding to the quantity of adsorbate required to form an adsorbed monolayer per unit mass of adsorbent $\left(\mathrm{mg} \mathrm{g}^{-1}\right)$, and $b$ is a Langmuir constant related to the binding energy of the sorption system $\left(\mathrm{L} \mathrm{g}^{-1}\right)$.

During the adsorption process, micropores can effectively capture guest $\mathrm{Cr}(\mathrm{VI})$ ions from the external environment due to the strong adsorption potential of the micropores. Meanwhile, at a low $\mathrm{pH}$ value $(\mathrm{pH} 3)$, fast protonation of the sample's surface active sites $\mathrm{X}-\mathrm{OH}$ $(\mathrm{X}=\mathrm{Fe}, \mathrm{C})$ form more $\mathrm{X}-\mathrm{OH}_{2}{ }^{+}$groups and hence can adsorb $\mathrm{HCrO}_{4}^{-}$through electrostatic adsorption [12,55]. As known, the redox potential $\left(E_{0}\right)$ of the $\mathrm{Cr}(\mathrm{VI}) / \mathrm{Cr}(\mathrm{III})$ system depends upon solution $\mathrm{pH}, 1.3 \mathrm{~V}$ at $\mathrm{pH} 1$ and $0.68 \mathrm{~V}$ at $\mathrm{pH}$. Due to the high positive redox potential of $\mathrm{Cr}(\mathrm{VI})$ in acidic solution, $\mathrm{Cr}(\mathrm{VI})$ is reduced and unstable in the presence of electron donors. It has been accepted that ox- ygen-containing functional groups on the carbon matrix surfaces such as ketone, carboxylic and hydroxyl groups, can play a role as electron donors [60]. Electron transfer between the adsorbents and $\mathrm{Cr}(\mathrm{VI})$ leads to oxidation of the carbon surface [55], forming new oxygen-containing functional groups. This is confirmed by the FTIR spectrum of Fe-HCSs-Zn-910 after adsorbing Cr(VI) (Fig. 3d). The peaks at 1632 and $1200 \mathrm{~cm}^{-1}$ are assigned to carboxyl and lactone group vibrations, respectively. Analysis of the adsorption supernatant fluid using inductively coupled plasma optical emission spectrometry after $24 \mathrm{~h}$, shows no detectable chromium and only $0.44 \mathrm{wt} . \%$ of the total Fe content of this sample. Hence, the reduced $\mathrm{Cr}$ (III) can further conduct complexation with the newly formed oxygen functional groups on the carbon surface [55]. This hypothesis is confirmed by the stronger bands at ca. 774 and $901 \mathrm{~cm}^{-1}$ (Fig. 3d), which are from intrinsic vibrations of the $\mathrm{Cr}-\mathrm{O}$ and $\mathrm{Cr}=\mathrm{O}$ bonds [22]. It is noteworthy that little of the $\gamma-\mathrm{Fe}_{2} \mathrm{O}_{3}$ embedded in the carbon matrix will dissolve in the acidic solution, which further demonstrates that the carbonaceous host matrix to some extent acts as a protective screen to save the guest iron-based nanoparticles from being leached by the surrounding chemicals. 
$\mathrm{Cr}(\mathrm{VI})$ uptake onto these synthesized magnetic microporous hollow carbon nanospheres is identified as a physicochemical process, including intense electrostatic adsorption $[12,55]$ due to the formation of more $\mathrm{X}-\mathrm{OH}_{2}{ }^{+}$ $(\mathrm{X}=\mathrm{Fe}, \mathrm{C})$ groups, followed by a redox process in which some of the $\mathrm{Cr}(\mathrm{VI})$ is reduced into less toxic $\mathrm{Cr}(\mathrm{III})$ $[13,14,18,57,61,62]$. Meanwhile, the reduced $\mathrm{Cr}$ (III) could further conduct complexation with the newly formed oxygen functional groups of the carbon surface.

\section{CONCLUSION}

Microporous hollow carbon nanospheres were obtained by heating HPSs- $\mathrm{Zn}$ to $910^{\circ} \mathrm{C}$. Owing to the presence of carboxyl functional groups in the hollow polymer spheres, zinc ions can be introduced. During carbonization, high temperature treatment results in the reduction of $\mathrm{Zn}^{2+}$ to metallic $\mathrm{Zn}$ and subsequent evaporation of $\mathrm{Zn}$, consequently forming nanospaces and nanopaths in the carbon shell. These microporous hollow carbon spheres could be further modified to fabricate a highly efficient $\mathrm{Cr}$ (VI) adsorbent, as demonstrated by magnetic microporous hollow carbon spheres with anchored magnetic $\gamma-\mathrm{Fe}_{2} \mathrm{O}_{3}$ nanoparticles. When examined as an absorbent for $\mathrm{Cr}(\mathrm{VI})$ removal, this material exhibited a high adsorption capacity and fast adsorption kinetics. Its maximum adsorption capacity of $\mathrm{Cr}(\mathrm{VI})$ per weight of adsorbent is $233.1 \mathrm{mg} \mathrm{g}^{-1}$. FTIR analysis on the magnetic microporous hollow carbon nanospheres before and after adsorbing $\mathrm{Cr}(\mathrm{VI})$, showed $\mathrm{Cr}(\mathrm{VI})$ uptake to be a physicochemical process, including intense electrostatic adsorption due to the formation of $\mathrm{X}-\mathrm{OH}_{2}{ }^{+}(\mathrm{X}=\mathrm{Fe}, \mathrm{C})$ groups, followed by a redox process in which some of the $\mathrm{Cr}(\mathrm{VI})$ is reduced to less toxic $\mathrm{Cr}(\mathrm{III})$. The reduced $\mathrm{Cr}$ (III) can then further complexation with the newly formed oxygen functional groups on the carbon surfaces.

Received 16 July 2015; accepted 10 August 2015; published online 19 August 2015

1 Ali I. New generation adsorbents for water treatment. Chem Rev, 2012, 112: 5073-5091

2 Miretzky P, Cirelli AF. Cr(VI) and Cr(III) removal from aqueous solution by raw and modified lignocellulosic materials. J Hazard Mater, 2010, 180: 1-19

3 Sun X, Yang L, Li Q, et al. Amino-functionalized magnetic cellulose nanocomposite as adsorbent for removal of $\mathrm{Cr}(\mathrm{VI})$ : synthesis and adsorption studies. Chem Eng J, 2014, 241: 175-183

4 Qiu B, Guo J, Zhang X, et al. Polyethylenimine facilitated ethyl cellulose for hexavalent chromium removal with a wide $\mathrm{pH}$ range. ACS Appl Mater Interfaces, 2014, 6: 19816-19824

5 Yang Y, Wang G, Deng Q, Ng DHL, Zhao H. Microwave-assisted fabrication of nanoparticulate $\mathrm{TiO}_{2}$ microspheres for synergistic photocatalytic removal of $\mathrm{Cr}(\mathrm{VI})$ and methyl orange. ACS Appl Mater Interfaces, 2014, 6: 3008-3015
6 Zhong LS, Hu JS, Liang HP, et al. Self-assembled 3D flowerlike iron oxide nanostructures and their application in water treatment. Adv Mater, 2006, 18: 2426-2431

7 Liu Z, Chen L, Zhang L, et al. Ultrafast Cr(VI) removal from polluted water by microwave synthesized iron oxide submicron wires. Chem Commun, 2014, 50: 8036-8039

8 Wei Z, Xing R, Zhang X, et al. Facile template-free fabrication of hollow nestlike $\alpha-\mathrm{Fe}_{2} \mathrm{O}_{3}$ nanostructures for water treatment. ACS Appl Mater Interfaces, 2013, 5: 598-604

$9 \mathrm{Mu} \mathrm{Y}, \mathrm{Ai} \mathrm{ZH}$, Zhang LZ, Song FH. Insight into core-shell dependent anoxic $\mathrm{Cr}(\mathrm{VI})$ removal with $\mathrm{Fe} @ \mathrm{Fe}_{2} \mathrm{O}_{3}$ nanowires: indispensable role of surface bound Fe(II). ACS Appl Mater Interfaces, 2015, 7: 1997-2005

$10 \mathrm{Hu}$ J, Chen G, Lo IM. Removal and recovery of Cr(VI) from wastewater by maghemite nanoparticles. Water Res, 2005, 39: 4528-4536

11 Wang P, Lo IM. Synthesis of mesoporous magnetic $\gamma-\mathrm{Fe}_{2} \mathrm{O}_{3}$ and its application to $\mathrm{Cr}(\mathrm{VI})$ removal from contaminated water. Water Res, 2009, 43: 3727-3734

12 Baikousi M, Bourlinos AB, Douvalis A, et al. Synthesis and characterization of $\gamma-\mathrm{Fe}_{2} \mathrm{O}_{3} /$ carbon hybrids and their application in removal of hexavalent chromium ions from aqueous solutions. Langmuir, 2012, 28: 3918-3930

13 Liu Y, Wang Y, Zhou S, et al. Synthesis of high saturation magnetization superparamagnetic $\mathrm{Fe}_{3} \mathrm{O}_{4}$ hollow microspheres for swift chromium removal. ACS Appl Mater Interfaces, 2012, 4: 4913-4920

14 Liu G, Deng Q, Wang H, et al. Synthesis and characterization of nanostructured $\mathrm{Fe}_{3} \mathrm{O}_{4}$ micron-spheres and their application in removing toxic $\mathrm{Cr}$ ions from polluted water. Chemistry, 2012, 18: 13418-13426

15 Zhang WB, Deng M, Sun CX, Wang SB. Ultrasound-enhanced adsorption of chromium(VI) on $\mathrm{Fe}_{3} \mathrm{O}_{4}$ magnetic particles. Ind Eng Chem Res, 2014, 53: 333-339

16 Parsons JG, Hernandez J, Gonzalez CM, Gardea-Torresdey JL. Sorption of $\mathrm{Cr}(\mathrm{III})$ and $\mathrm{Cr}(\mathrm{VI})$ to high and low pressure synthetic nano-magnetite $\left(\mathrm{Fe}_{3} \mathrm{O}_{4}\right)$ particles. Chem Eng J, 2014, 254: 171-180

17 Dui J, Zhu G, Zhou S. Facile and economical synthesis of large hollow ferrites and their applications in adsorption for $\mathrm{As}(\mathrm{V})$ and Cr(VI). ACS Appl Mater Interfaces, 2013, 5: 10081-10089

18 Chowdhury SR, Yanful EK, Pratt AR. Chemical states in XPS and raman analysis during removal of $\mathrm{Cr}(\mathrm{VI})$ from contaminated water by mixed maghemite-magnetite nanoparticles. J Hazard Mater, 2012, 235-236: 246-256

19 Zhang XQ, Guo Y, Li WC. Efficient removal of rexavalent chromium by high surface area $\mathrm{Al}_{2} \mathrm{O}_{3}$ rods. RSC Adv, 2015, 5: 25896-25903

20 Neghlani PK, Rafizadeh M, Taromi FA. Preparation of aminated-polyacrylonitrile nanofiber membranes for the adsorption of metal ions: comparison with microfibers. J Hazard Mater, 2011, 186: 182-189

21 Wang Y, Zou B, Gao T, et al. Synthesis of orange-like $\mathrm{Fe}_{3} \mathrm{O}_{4} / \mathrm{PPy}$ composite microspheres and their excellent $\mathrm{Cr}(\mathrm{VI})$ ion removal properties. J Mater Chem, 2012, 22: 9034-9040

22 Bhaumik M, Maity A, Srinivasu VV, Onyango MS. Enhanced removal of $\mathrm{Cr}(\mathrm{VI})$ from aqueous solution using polypyrrole $/ \mathrm{Fe}_{3} \mathrm{O}_{4}$ magnetic nanocomposite. J Hazard Mater, 2011, 190: 381-390

23 Avila M, Burks T, Akhtar F, et al. Surface functionalized nanofibers for the removal of chromium(VI) from aqueous solutions. Chem Eng J, 2014, 245: 201-209

24 Chen JH, Xing HT, Guo HX, et al. Investigation on the adsorption properties of $\mathrm{Cr}(\mathrm{VI})$ ions on a novel graphene oxide (GO) based composite adsorbent. J Mater Chem A, 2014, 2: 12561-12570

25 Arulkumar M, Thirumalai K, Sathishkumar P, Palvannan T. Rapid removal of chromium from aqueous solution using novel prawn shell activated carbon. Chem Eng J, 2012, 185-186: 178-186 
26 Chen S, Yue Q, Gao B, Li Q, Xu X. Removal of Cr(VI) from aqueous solution using modified corn stalks: characteristic equilibrium kinetic and thermodynamic study. Chem Eng J, 2011, 168: 909-917

27 Yin C, Aroua M, Daud W. Review of modifications of activated carbon for enhancing contaminant uptakes from aqueous solutions. Sep Purif Technol, 2007, 52: 403-415

28 Liu H, Liang S, Gao J, et al. Enhancement of $\mathrm{Cr}(\mathrm{VI})$ removal by modifying activated carbon developed from zizania caduciflora with tartaric acid during phosphoric acid activation. Chem Eng J, 2014, 246: 168-174

29 Stein A, Wang Z, Fierke MA. Functionalization of porous carbon materials with designed pore architecture. Adv Mater, 2009, 21: 265-293

30 Xu GR, Wang JN, Li CJ. Preparation of hierarchically nanofibrous membrane and its high adaptability in hexavalent chromium removal from water. Chem Eng J, 2012, 198-199: 310-317

31 Liu DH, Guo Y, Zhang LH, et al. Switchable transport strategy to deposit active $\mathrm{Fe} / \mathrm{Fe}_{3} \mathrm{C}$ cores into hollow microporous carbons for efficient chromium removal. Small, 2013, 9: 3852-3857

32 Zhang LH, Sun Q, Liu DH, Lu AH. Magnetic hollow carbon nanospheres for removal of chromium ions. J Mater Chem A, 2013, 1: 9477-9483

33 Zhu J, Wei S, Gu H, et al. One-pot synthesis of magnetic graphene nanocomposites decorated with core@double-shell nanoparticles for fast chromium removal. Environ Sci Technol, 2012, 46: 977-985

34 Gupta VK, Agarwal S, Saleh TA. Chromium removal by combining the magnetic properties of iron oxide with adsorption properties of carbon nanotubes. Water Res, 2011, 45: 2207-2212

35 Zhang D, Wei S, Kaila C, et al. Carbon-stabilized iron nanoparticles for environmental remediation. Nanoscale, 2010, 2: 917-919

36 Zhu J, Gu H, Guo J, et al. Mesoporous magnetic carbon nanocomposite fabrics for highly efficient $\mathrm{Cr}(\mathrm{VI})$ removal. J Mater Chem A, 2014, 2: 2256-2265

37 Cui HJ, Cai JK, Zhao H, et al. One step solvothermal synthesis of functional hybrid $\gamma-\mathrm{Fe}_{2} \mathrm{O}_{3} /$ carbon hollow spheres with superior capacities for heavy metal removal. J Colloid Interface Sci, 2014, 425: 131-135

38 Wang GH, Sun Q, Zhang R, et al. Weak acid-base interaction induced assembly for the synthesis of diverse hollow nanospheres. Chem Mater, 2011, 23: 4537-4542

39 Lu AH, Li WC, Salabas EL, Spliethoff B, Schüth F. Low temperature catalytic pyrolysis for the synthesis of high surface area nanostructured graphitic carbon. Chem Mater, 2006, 18: 2086-2094

$40 \mathrm{Lu} \mathrm{AH}$, Li WC, Hao GP, et al. Easy synthesis of hollow polymer, carbon, and graphitized microspheres. Angew Chem Int Ed, 2010, 49: 1615-1618

41 Qian D, Lei C, Wang EM, Li WC, Lu AH. A method for creating microporous carbon materials with excellent $\mathrm{CO}_{2}$ adsorption capacity and selectivity. ChemSusChem, 2014, 7: 291-298

42 Sun Q, Guo CZ, Wang GH, et al. Fabrication of magnetic yolkshell nanocatalysts with spatially resolved functionalities and high activity for nitrobenzene hydrogenation. Chem Eur J, 2013, 19: 6217-6220

43 Wang H, Yuan X, Wu Y, et al. Adsorption characteristics and behaviors of graphene oxide for $\mathrm{Zn}$ (II) removal from aqueous solution. Appl Surf Sci, 2013, 279: 432-440

44 Simon-Kutscher J, Gericke A, Hühnerfuss H. Effect of bivalent Ba, $\mathrm{Cu}, \mathrm{Ni}$, and $\mathrm{Zn}$ cations on the structure of octadecanoic acid monolayers at the air-water interface as determined by external infrared reflection-absorption spectroscopy. Langmuir, 1996, 12: 1027-1034

45 Cesano F, Scarano D, Bertarione S, et al. Synthesis of ZnO-carbon composites and imprinted carbon by the pyrolysis of $\mathrm{ZnCl}_{2}$-catalyzed furfuryl alcohol polymers. J Photochem Photobiol A, 2008,
196: $143-153$

46 Zhang L, Hu YH. A systematic investigation of decomposition of nano $\mathrm{Zn}_{4} \mathrm{O}\left(\mathrm{C}_{8} \mathrm{H}_{4} \mathrm{O}_{4}\right)_{3}$ metal-organic framework. J Phys Chem C, 2010, 114: 2566-2572

47 Jiang HL, Liu B, Lan YQ, et al. From metal-organic framework to nanoporous carbon: toward a very high surface area and hydrogen uptake. J Am Chem Soc, 2011, 133: 11854-11857

48 Zhang H, Yan Y, Yang L. Preparation of activated carbon from sawdust by zinc chloride activation. Adsorption, 2010, 16: 161-166

49 Qian Q, Machida M, Tatsumoto H. Preparation of activated carbons from cattle-manure compost by zinc chloride activation. Bioresour Technol, 2007, 98: 353-360

50 Khalili NR, Campbell M, Sandi G, Golaś J. Production of microand mesoporous activated carbon from paper mill sludge. Carbon, 2000, 38: 1905-1915

51 Caturla F, Molina-Sabio M, Rodríguez-Reinoso F. Preparation of activated carbon by chemical activation with $\mathrm{ZnCl}_{2}$. Carbon, 1991, 29: 999-1007

52 Kim J, Kim HS, Lee N, et al. Multifunctional uniform nanoparticles composed of a magnetite nanocrystal core and a mesoporous silica shell for magnetic resonance and fluorescence imaging and for drug delivery. Angew Chem Int Ed, 2008, 47: 8438-8441

53 Lu AH, Nitz JJ, Comotti M, et al. Spatially and size selective synthesis of Fe-based nanoparticles on ordered mesoporous supports as highly active and stable catalysts for ammonia decomposition. J Am Chem Soc, 2010, 132: 14152-14162

54 Wu ZX, Li W, Webley PA, Zhao DY. General and controllable synthesis of novel mesoporous magnetic iron oxide@carbon encapsulates for efficient arsenic removal. Adv Mater, 2012, 24: 485-491

55 Liu W, Zhang J, Zhang C, Ren L. Preparation and evaluation of activated carbon-based iron-containing adsorbents for enhanced Cr(VI) removal: mechanism study. Chem Eng J, 2012, 189-190: 295-302

56 Ho YS, McKay G. Pseudo-second order model for sorption processes. Process Biochem, 1999, 34: 451-465

57 Li R, Liu L, Yang F. A study on the reduction behaviors of $\mathrm{Cr}(\mathrm{VI})$ on $\mathrm{Fe}_{3} \mathrm{O}_{4} /$ PANI. Procedia Environ Sci, 2013, 18: 522-527

58 Babu BV, Gupta S. Adsorption of $\mathrm{Cr}(\mathrm{VI})$ using activated neem leaves: kinetic studies. Adsorption, 2007, 14: 85-92

59 Fan L, Luo C, Sun M, Qiu H. Synthesis of graphene oxide decorated with magnetic cyclodextrin for fast chromium removal. J Mater Chem, 2012, 22: 24577-24583

60 Babel S, Kurniawan TA. Cr(VI) removal from synthetic wastewater using coconut shell charcoal and commercial activated carbon modified with oxidizing agents and/or chitosan. Chemosphere, 2004, 54: 951-967

61 Aggarwal D, Goyal M, Bansal RC. Adsorption of chromium by activated carbon from aqueous solution. Carbon, 1999, 37: 1989-1997

62 Deng S, Bai R. Removal of trivalent and hexavalent chromium with aminated polyacrylonitrile fibers: performance and mechanisms. Water Res, 2004, 38: 2423-2431

Acknowledgements The project was supported by the National Natural Science Foundation of China (21225312) and the Fundamental Research Funds for the Central Universities (DUT14ZD209).

Author contributions Zhang LH designed and engineered the samples; Sun Q helped in the fabrication of devices and methods of characterization; Zhang LH and Yang C performed the experiments; Lu AH supervised the projects and carefully reviewed and modified this manuscript. All authors contributed to the general discussion.

Conflict of interest The authors declare that they have no conflict of interest. 


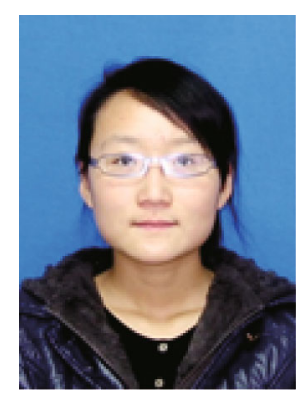

Lu-Hua Zhang was born in 1990. She received her BSs degree from Qingdao University of Science \& Technology, Qingdao, China, in 2011. Then she joined Dalian University of Technology and conducted research under the supervision of Prof. An-Hui Lu. Her research interests include the controllable synthesis, surface modification and functionalization of magnetic carbon nanospheres.

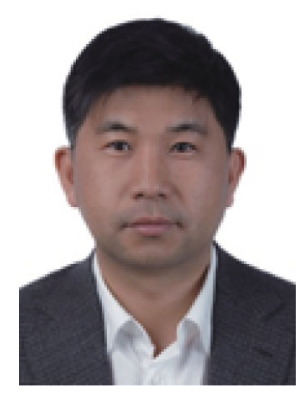

An-Hui Lu was born in 1972. He is currently a professor at the State Key Laboratory of Fine Chemicals, School of Chemical Engineering, Dalian University of Technology, Dalian, since 2008. He received his PhD degree from the Institute of Coal Chemistry, Chinese Academy of Sciences in 2001. After postdoctoral work (as a Max Planck research fellow and Alexander von Humboldt fellow) in the group of Prof. F. Schüth at Max-Planck-Institutfür Kohlenforschung, he was promoted to group leader in 2005. His research interests include designed synthesis of porous carbon-based solids, nanostructured energy-related materials, multifunctional magnetic nanomaterials, and their applications in heterogeneous catalysis, adsorption, energy storage, and conversion.

中文摘要 本文采用鳌合的锌物种作为制孔剂, 运用原位刻蚀的方法, 制备了具有丰富微孔的空心纳米炭球. 通过一步真空浸渍 $\mathrm{Fe}\left(\mathrm{NO}_{3}\right)_{3}$, 得到磁性纳米空心炭球 $\left(\gamma-\mathrm{Fe}_{2} \mathrm{O}_{3}\right.$ 含量为 $\left.14 \mathrm{wt} . \%\right)$, 其 $\mathrm{Cr}(\mathrm{VI})$ 吸附量可达 $233.1 \mathrm{mg} \mathrm{g}^{-1}$, 高于其它文献报道值. 结果表明: 聚合物母体中仅 负载 $8.6 \mathrm{wt}$.\%的 $\mathrm{Zn}^{2+}$ 能使炭球的微孔孔容积增加 $133 \%$, 比表面积增加 $86 \%$, 这是由于高温炭化过程中锌组分的挥发在炭壁上形成的微孔 孔道所致. 由于微孔的强吸附势和高的比面积, 磁性炭球在作为 $\mathrm{Cr}(\mathrm{VI})$ 吸附剂时, 表现出吸附速率快和吸附量高的优异性能. 吸附完成 后, 吸附剂可通过外加磁场回收. 